tion of the avoidable factor to the death; at best they can suggest that it was an associated factor.

Nevertheless the inquiry by Payne and colleagues managed to uncover a number of deaths that might have been prevented given competent practice. It should return to the problem after a year or two to determine whether the number of these sentinel events has fallen.

Inquiry into such events in young people should certainly be encouraged, and mechanisms should be developed to allow the incorporation of audit methods into the contracting process.

CHARLES WOLFE Senior lecturer in public health medicine

Department of Public Health Medicine,

Division of Community Health,

UMDS, St Thomas's Hospital,

London SE1 7EH
1 Chartton JRH, Hartley RM, Silver T, Holland WW. Geographical variation in mortality from conditions amenable to medical intervention in England and Wales. Lancet 1983;i:691-6

Rutstein DD, Berenberg $W$, Chalmers TC, Child CG, Fishman AP, Perrin EB. Measuring the quality of medical care: a clinical method. New Engl f Med 1976;294:548-88.

3 Holland WW, ed. The European Community atlas of "avoidable deaths," Vol II. Oxford: Oxford University Press, 1993. (Commission of the European Communities health services research series 6.)

4 Department of Health. Public health common data set England and Wales 1986-1990 London: DoH, 1991.

5 House of Commons Committee of Public Accounts. Quality of clinical care in National Health Service hospitals (Oth report). London: HMSO, 1989.

6 Wolfe CDA. Avoidable mortality. Foumal of Management in Medicine 1989;4:104-7

7 Buck N, Devlin HB, Lunn HN. The repon of the confidential enquiry into peroperative deaths. London: Nuffield Provincial Hospitals Trust, 1987.

8 Department of Health, Welsh Office, Scottish Home and Health Department, and Department of Health and Social Security, Northern Ireland. Report of confidential enquiries into maternal deaths in the United Kingdom 1985-1987. London: HMSO, 1991.

9 Department of Health. The health of the nation, key area handbook: coronary heart disease and stroke. London: DoH, 1993.

10 Ebrahim S. Clinical epidemiology of stroke. Oxford: Oxford Medical Publications, 1990.

11 Payne JN, Milner PC, Saul C, Bowns IR, Hannay DR, Ramsau LE. A locally-based confidential enquiry into stroke and hypertensive deaths (CESHAD): the methodology and illustrative results from an average sized health district. $B M Y$ 1993;307:1027-30.

12 Singal GM, Stilwell PJ, Chambers J, Clews B. A confidential enquiry into premature preventable deaths. Pilot study. Walsall: Walsall Health Authority, 1985.

\title{
A model for British medical education
}

\section{The model seems to be agreed: now it needs implementing}

The way medical students are trained has been widely criticised in recent years. Grossly overloaded curriculums, rote learning, the inclusion of topics with little obvious relevance to medical practice, and inappropriate teaching methods have been blamed for stifling enthusiasm, inhibiting students' ability to benefit from postgraduate and continuing training, and even contributing to stress and depression in junior doctors. ${ }^{1}$ The criticisms have come from students themselves, from medical educationalists, and also from staff at some of the world's most prestigious medical schools. ${ }^{23}$

In Britain the General Medical Council, which is ultimately responsible for approving undergraduate education, has been expressing its concerns for decades, ${ }^{4}$ and in May 1991 it issued a discussion document that has since become the focus for wide debate about the problems of medical education in Britain. ${ }^{5}$ In August the council published its revised recommendations on undergraduate medical education, based largely on the responses to its earlier document. ${ }^{6}$ Formal consultations on the draft paper have just closed, and the GMC's education committee is due to report to the full council next month.

The council believes that the recommendations will promote an approach to medical education that will "differ substantially from those of the traditional curriculum." One of the main aims is to reduce the factual overload that has dogged the medical curriculum since at least the last century. As expected, the council has opted for a model with a core set of courses and "special study modules." All students will study core courses for part of the time (the current document does not specify how much, but two thirds of the total time is likely). The rest of their time will be spent on personal in depth study of subjects of their own choosing. (The term "options" used in the discussion document has been dropped, presumably because too many people concluded that these studies would not be compulsory.)

Despite stating that a core curriculum is likely to create "an increased degree of standardisation" the council has so far shown no interest in defining a national core curriculum. This will certainly be criticised in the medical schools' responses. Many schools are unwilling to embark on major reforms of their curriculums in case they "get it wrong" and come up with a core that the General Medical Council declines to approve. Some have even suggested that the council has a statutory obligation under the 1983 Medical Act to define the core. (The act requires the council's education committee to "determine the extent of the knowledge and skill which is required.") An inquiry organised by the King's Fund in 1990 called for a nationally defined core. ${ }^{2}$

Nevertheless, the General Medical Council is likely to resist these calls. Any attempt to define a national core would require an unprecedented amount of time, effort, and money. Those who oppose the idea of a national core also express concerns about the opportunity it would create for outsiders such as governments and managers to influence its content. Some also fear (or hope) that a national core would lead eventually to national licensing examinations.

Everyone agrees, however, that if the council wants schools to adopt the model of a core and modules it must give more guidance about how to implement this. The draft document hopes that "the practice of sharing of ideas and of learning materials... will become a tradition... in order to reduce unnecessary duplication of effort." The least that the council should do is to set up and support an infrastructure that will guarantee that this happens, perhaps by building on the foundation provided by the "change in medical education" network already established by the King's Fund.

Perhaps the bravest and most exciting element of the draft recommendations is the absence of any reference to traditional subjects and disciplines. There is talk of "human biology," "disease processes," and "principles of therapy" but no mention of anatomy, physiology, pathology, or pharmacology. This is combined with a strong emphasis on full vertical and horizontal integration of the courses. The basic and clinical sciences are to be taught together throughout the course, removing the traditional division between preclinical and clinical studies. Inevitably this will be greeted with wails of protest by those who wish to defend their departmental bastions. But the flexibility permitted by this document should provide an opportunity, once and for all, for individual specialties (especially the basic sciences) to prove their relevance and justify their inclusion in the undergraduate course.

Another important innovation is the inclusion of "skills objectives." Students will have to show proficiency in essential 
practical procedures before they can graduate. Only basic and advanced life support, venesection, and inserting an intravenous line are listed in the draft document, and medical schools will probably ask the council to extend this list. The council is to be commended for recognising that such skills need to be taught and tested. Their inclusion should help to reduce the stress felt by junior house officers expected to perform unfamiliar procedures with inadequate supervision on acutely ill patients in the middle of the night.

With their emphasis on reduced factual content, self directed learning, integration of traditional subjects, and training in practical skills, these draft recommendations should help to overcome many of the problems of traditional medical courses. This will happen, however, only if the General Medical Council is committed to ensuring that its recommendations are acted on. It has limited powers to enforce its recommendations, and those it has, like withdrawing recognition from a course, are draconian. It should realise, however, that there is now a groundswell of approval for the ideas contained in its latest document and should take that as a mandate for their enforcement. When the council issues its definitive document it must be accompanied by a clearly defined timetable for implementation and a firm statement that schools failing to achieve this will be penalised.

STELLALOWRY

Assistant secretary

BMA,

London WC1H 9JP

1 Lowry S. Medical education. London: BMJ Publishing Group, 1993.

2 Towle A. Critical thinking: the future of undergraduate medical education. London: King's Fund Centre, 1991.

3 Tosteson DC. New pathways in general medical education. N Engl f Med 1990;322:234-8.

4 General Medical Council. Recommendations as to the medical curriculum. London: GMC, 1957.

5 General Medical Council. Undergraduate medical education. London: GMC, 1991 (Discussion document.)

6 General Medical Council. 1993 Recommendations on undengraduate medical education (draft). London: GMC, 1993.

\title{
Is an eye pad needed in cases of corneal abrasion?
}

\author{
No, but exclude more serious trauma first
}

Although the transparent cornea acts primarily as a lens, it also shields the contents of the eye. Protection is provided by the corneal epithelium, which is supplied by a network of sensory nerves that cause extreme pain and immediate blepharospasm when stimulated. Injuries to the corneal epithelium have traditionally been treated with antibiotic ointment and an eye pad, but evidence has emerged that the eye pad may not only be ineffective but also retard healing.

Four types of lesions occur after corneal trauma: epithelial defects, epithelial and superficial stromal defects, deep stromal defects, and full thickness defects. Corneal abrasions affect only the epithelium and cause disablement for up to three days. Abrasions are usually due to accidents caused by such items as twigs, the uncontrolled pages of a newspaper, and unrestrained fingernails. Immediately there is agonising pain, watering, and photophobia, which are relieved by applying temporary pressure on the closed eye. Such injuries account for a tenth of new cases in some eye casualty units. ${ }^{1}$ The history itself is enough to deduce the diagnosis, but examination is necessary to exclude foreign bodies, hyphaemas, and serious corneal lacerations.

Epithelial wounds heal primarily by the migration and proliferation of cells that slide in to repair the deficit. A recent study hàs shown that patients treated with antibiotic ointment and mydriatic drops alone showed significantly faster healing than those given an occlusive eye pad and bandage as well. ${ }^{2}$ In fact, two fifths of patients had to remove their pads because of discomfort. The explanation is that a firm eye pad may produce an adverse corneal environment, applying pressure to the regenerating epithelium as well as reducing oxygenation. Similarly, after the removal of a corneal foreign body healing occurs almost always within 24 hours, and an eye pad seems to confer no extra benefit. ${ }^{3}$

On the other hand, double padding - padding both eyes- has been reported to activate healing more rapidly than a single pad, ${ }^{4}$ although double padding has not been compared with no padding. Double padding probably works through reducing ocular movement. Also, porcine collagen shieldstranslucent and placed on the eyeball-reduce pain more quickly and are more comfortable than conventional eye patches and allow immediate visual recovery. ${ }^{5}$ They are, however, expensive and available only in hospital eye departments.

The evidence is that eye pads for corneal abrasions and foreign bodies serve no useful purpose and may even delay wound healing. These moderately benign and common conditions should therefore be treated with topical antibiotics and mydriatics alone. The antibiotic can be given as dropsfor example, chloramphenicol, framycetin, fusidic acid, or neomycin sulphate-and a short acting mydriatic such as tropicamide will relieve discomfort, though it will also temporarily reduce accommodation. Such simple remedies can be given in general practitioners' surgeries, provided that care is taken to exclude other conditions that may masquerade as abrasions. These conditions, such as dendritic ulcers due to herpes simplex virus, are best identified by staining the cornea with fluorescein and examining it with a blue light source. ${ }^{6}$

D LEASTY

Bristol Eye Hospital,

Professor of ophthalmology

Bristol BS1 2LX

1 Chiapella AP, Rosenthai AR. One year in an eye casualty. Br 7 Ophthalmol 1985;69:865-70.

2 Kirkpatrick JNP, Hoh HB, Cook SD. No eye pad for corneal abrasion. Eye 1993;7:468-71.

3 Hulbert MFG. Efficacy of eyepad in corneal healing after corneal foreign body removal. Lance 1991;337:643.

4 Gregersen PL, Ottavay E, Kobayashe C, Hansen SE, Bohnstedt J. Treatment of comeal abrasion. Ugeskr Laeger 1991;153:2123-4.

5 Wedge CI, Rootmen DS. Collagen shields: efficacy, safety and comfort in the treatment of huma traumatic corneal abrasion and effect on vision in healthy eyes. Can 7 Ophthalmol 1992;27:295-8.

6 Ragge N, Easty DL. Immediate eye care. London: Wolfe, 1991. 